\title{
PREVALENCE, PATTERNS AND PERCEPTION OF TOBACCO USE AMONG HEALTH SCIENCES UNDERGRADUATE STUDENTS IN MALAYSIA: A CROSS- SECTIONAL STUDY
}

\author{
Priyadarshini Ramamurthy, Bennete Fernandes and Avita Rath \\ Faculty of Dentistry, SEGi University, Kota Damansara, Selangor, Malaysia \\ Corresponding author: Priyadarshini Ramamurthy \\ Email: priyadarshiniramamurthy@segi.edu.my
}

\begin{abstract}
The aim of this study was to determine the prevalence and patterns of tobacco use among health sciences undergraduate students. A cross-sectional study was conducted among 422 students in four health sciences faculties at a private university in Kota Damansara, Selangor Malaysia. Data was collected through a self-administrated validated questionnaire, adopted and modified from the Global Youth Tobacco Survey. The survey was administered online using a Google Form for the participants to fill. Data was analysed using SPSS version 22. Descriptive statistics was used to express results in percentage. Chi-square test and multivariable logistic regression was used to test the association of smoking status and demographic variables. $p$ value of $<0.05$ was considered as statistically significant. Results showed that more than $90 \%$ of the respondents were aware of the harmful effects of tobacco and effects of passive smoking. About one fifth of the participants had used tobacco (19\%) in our study. Out of the tobacco users, $95 \%$ had used tobacco in more than one form. The most important reasons for smoking were peer pressure (36\%) and stress (35\%). No significant differences were found between age, faculty, year of study, or nationality, with the use of tobacco. Multivariable logistic regression analysis showed significant gender differences in smoking with more smokers among males than females. In conclusion, about one fifth of the health science undergraduate students had used tobacco products in our study reflecting a seemingly inappropriate portrait as compared to their future careers as health professionals. Therefore, there is an urgent need for reinforcement of education and assistance on quitting tobacco usage among the undergraduates of health science faculties.
\end{abstract}

Keywords: tobacco use; health sciences students; prevalence, pattern

\section{INTRODUCTION}

Tobacco, a plant extract, bears undeniable contributions in various types of diseases ${ }^{1}$. Tobacco smoking is considered as a global epidemic. Tobacco kills more than 8 million people every year. More than 7 million of those deaths are the result of direct tobacco use while around 1.2 million are the result of non-smokers being exposed to second-hand smoke ${ }^{2}$. Despite being aware of such alarming information, tobacco users are widespread across the globe, including Malaysia. The National Health and Morbidity Survey in 2015 showed that the prevalence of tobacco smoking among individuals aged 15 years and older in Malaysia was approximately $22.8 \%{ }^{3}$.

In the past few years, smoking cessation has emerged as an evidence based approach to reduce health risks and improve the quality of life among smokers ${ }^{4}$. As tobacco is highly addictive, cessation attempts need to be supported by health care professionals to achieve long-term abstinence. Health professionals can promote smoking cessation both as advisers and behavioral role models for the people ${ }^{5,6}$.

One of the strategies advocated by WHO to reduce the number of smoking related morbidity and mortality events is by involving healthcare providers and healthcare institutions in tobacco prevention and cessation counseling ${ }^{7}$. There is evidence that smoking cessation interventions are effective when delivered by non-physician health professional groups such as nurses ${ }^{8}$, dentists ${ }^{9}$, dental hygienists ${ }^{10}$, and pharmacists ${ }^{11}$.

Undergraduate students from health science faculties are the future health professionals of any nation. It is imperative that they are aware of the consequences of harmful substances like tobacco in the larger interest of society, as they can play a pivotal role in creating awareness about tobacco usage among the youth. Unfortunately, many international studies indicate that a high percentage of healthcare students are occasional smokers themselves ${ }^{12}$. Data from a global study spanning 70 countries showed a wide range of prevalence of tobacco habits among health professional students, with the highest prevalence of smoking in European countries, followed by America and other forms of tobacco use were found to be higher in Eastern Mediterranean ${ }^{13}$.

When it comes to the Malaysian scenario, some data is available on prevalence of smoking habits among medical students ${ }^{14}$. However, no data is available on the prevalence and patterns of 
tobacco habits among other healthcare students. Hence, we conducted this study to determine the prevalence and patterns of tobacco habits among healthcare students of a private university in Malaysia, so that recommendations could be made for educating them about its consequences and reinforcing their important role in tobacco cessation.

\section{METHODS}

This cross-sectional study was conducted at a private university in Selangor, on undergraduate students of health sciences faculties that included faculty of medicine, faculty of dentistry, faculty of pharmacy and faculty of optometry and visual sciences. About 500 students enrolled from among the four faculties, were invited to take part in this study, without any bar for age, gender, or ethnicity. Ethical clearance was obtained from the institutional ethics committee. Necessary permissions were obtained from the respective faculties and informed consent was obtained from all the student participants, after explaining the objectives of the study. Students who did not consent to take part, were excluded.

Data was collected through a self-administrated questionnaire, adopted and modified from the Global Youth Tobacco Survey ${ }^{15}$. The questionnaire consisted of 27 questions of both close and openended types. The questionnaire included sections on demography, knowledge about tobacco, its products and its effects, access to tobacco and reasons for using it, attitude towards quitting, and practices related to tobacco use. Validation of the questionnaire for clarity was carried out on 20 randomly selected students who were not part of the study. Minor modifications were made based on students' feedback.

Survey was administered online using a Google Form for the participants to fill. Survey link was sent via emails and WhatsApp. One month time was given for the participants to reply. Reminders were sent in between for participants to take part in the survey via class WhatsApp group.

\section{Statistical analysis}

Data was analysed using SPSS version 22 (IBM Corporation, Armonk, NY, USA) using frequencies $(\mathrm{n})$, percentages (\%), chi-square tests and multivariable logistic regression analysis. Level of significance was set at $p<0.05$.

\section{RESULTS}

Out of the 500 students, 422 responded to the survey, yielding a response rate of about $84.4 \%$. Table 1 shows the demographic distribution of the participants. Majority of the participants were below 25 years of age. About 30\% of them were males and $70 \%$ were females.
Table 2 shows responses of the participants to the questions pertaining to their knowledge about tobacco. Out of 422 participants, 409 (96.9\%) of them had heard about tobacco. More than $90 \%$ of them were aware of the harmful effects of tobacco and effects of passive smoking, and had seen anti-tobacco warnings previously.

Pertaining to the use of tobacco, out of 422 respondents, 80 (19\%) of them had used tobacco in some form or the other. Out of the 80 tobacco users in our study, 76 (95\%) had used tobacco in more than one form; cigarette and shisha, cigarette and vaping, shisha and vaping, or all the three. Graph 1 shows the distribution of the participants according to the type of tobacco used. Among the tobacco users, majority of them smoked cigarettes (75.7\%) and shisha (71.3\%). About $40 \%$ of the tobacco users in our study started using tobacco products when they were 10-20 years old. However, about 39\% did not remember the age when they first started.

Pertaining to the questions regarding their access to tobacco products, $56 \%$ of the tobacco users had bought it on their own from a store, while the remaining $44 \%$ of the users got it from their friends. Also, for more than half of the tobacco users in our study (55\%), friends had influenced them to use tobacco, as compared to $42.5 \%$ who started to use tobacco because of self-desire.

The main reasons for tobacco use among the participants were peer pressure (36\%) and stress (35\%) followed by self-enjoyment $(25 \%)$. Among the tobacco users, about $73 \%$ of them were not regular users. Only about $7 \%$ used it more than three times a day.

When questions were asked pertaining to their attitude and willingness to quit tobacco, about $32.5 \%$ of the participants agreed that they had been previously advised by either their family members or friends to quit tobacco. However, only $11 \%$ were currently actually willing to quit tobacco if assistance was provided to them.

Table 3 shows the results of regression analysis. Results showed no significant differences between age, faculty, year of study or nationality with the use of tobacco with $p=0.102, p=0.361$, $p=0.681$ and $p=0.200$ respectively. However, prevalence of smoking was higher among males (30.8\%) than in females $(13.7 \%), O R=2.8,95 \% \mathrm{Cl}$ $1.69-4.61, \mathrm{p}<0.001$. Also, the percentage of tobacco users was higher among other races as compared to Chinese, Malay or Indians $(p=0.008)$.

No significant differences were found between any of the demographic variables and type of tobacco product used, with $p$ value $>0.05$ (Not shown in the table) 
Malaysian Journal of Public Health Medicine 2021, Vol. 21 (2): 88-94

Table 1: Socio-demographic characteristics of the participants

\begin{tabular}{|c|c|c|}
\hline Variable & Number (n) & Percentage \\
\hline \multicolumn{3}{|l|}{ Age } \\
\hline $16-20$ years & 176 & $41.7 \%$ \\
\hline 21- 25 years & 240 & $56.9 \%$ \\
\hline $26-30$ years & 06 & $1.4 \%$ \\
\hline \multicolumn{3}{|l|}{ Gender } \\
\hline Male & 130 & $30.8 \%$ \\
\hline Female & 292 & $69.2 \%$ \\
\hline \multicolumn{3}{|l|}{ Race } \\
\hline Chinese & 281 & $66.6 \%$ \\
\hline Malay & 67 & $15.9 \%$ \\
\hline Indian & 43 & $10.2 \%$ \\
\hline Others & 31 & $7.3 \%$ \\
\hline \multicolumn{3}{|l|}{ Nationality } \\
\hline Malaysian & 395 & $93.6 \%$ \\
\hline Non-Malaysian & 27 & $6.4 \%$ \\
\hline \multicolumn{3}{|l|}{ Faculty } \\
\hline Dentistry & 230 & $54.5 \%$ \\
\hline Medicine & 68 & $16.1 \%$ \\
\hline Pharmacy & 83 & $19.7 \%$ \\
\hline Optometry & 41 & $9.7 \%$ \\
\hline \multicolumn{3}{|l|}{ Year of Study } \\
\hline Year 1 & 121 & $28.7 \%$ \\
\hline Year 2 & 110 & $26.1 \%$ \\
\hline Year 3 & 74 & $17.5 \%$ \\
\hline Year 4 & 75 & $17.8 \%$ \\
\hline Year 5 & 42 & $10 \%$ \\
\hline
\end{tabular}

Table 2: Participants' responses to questions pertaining to knowledge about tobacco

\begin{tabular}{lcc}
\hline Questions & Yes & No \\
& & 13 \\
\hline Have you heard about tobacco? & 409 & $(3.1 \%)$ \\
& $(96.9 \%)$ & 4 \\
$\begin{array}{l}\text { Are you aware of the harmful effects of } \\
\text { tobacco? }\end{array}$ & 418 & $(0.9 \%)$ \\
$\begin{array}{l}\text { Are you aware of the effects of passive } \\
\text { smoking? }\end{array}$ & $(99.1 \%)$ & 39 \\
Have you seen anti-tobacco warnings ? & 383 & $(9.2 \%)$ \\
\end{tabular}




\section{Graph 1: Distribution of tobacco users based on type of tobacco used}

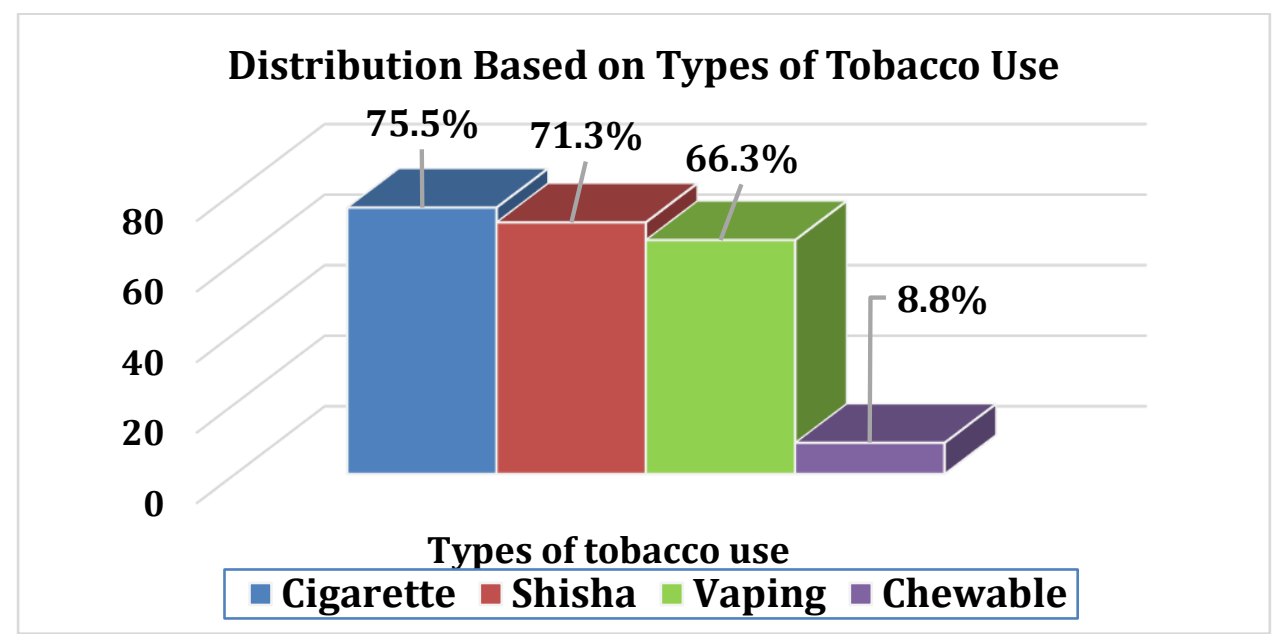

Table 3: Relationship between demographic variables and tobacco use.

\begin{tabular}{|c|c|c|c|c|c|c|c|c|}
\hline \multicolumn{2}{|c|}{ Demographic Factors } & \multirow{2}{*}{$\begin{array}{l}\begin{array}{l}\text { Tobacco } \\
\text { user }\end{array} \\
25(14.2 \%)\end{array}$} & \multirow{2}{*}{$\begin{array}{l}\begin{array}{l}\text { Not a tobacco } \\
\text { user }\end{array} \\
151(85.8 \%)\end{array}$} & \multirow{2}{*}{$\begin{array}{l}X^{2} \\
4.56\end{array}$} & \multirow{2}{*}{$\begin{array}{l}p \\
0.102\end{array}$} & \multirow{2}{*}{$\begin{array}{l}\text { OR } \\
0.75\end{array}$} & \multicolumn{2}{|c|}{$\begin{array}{l}\mathrm{Cl}(95 \%) \\
\text { Lower Upper }\end{array}$} \\
\hline & $\leq 20$ years & & & & & & 0.070 & 8.166 \\
\hline \multirow[t]{2}{*}{ Age Group } & $>20$ years & $55(22.5 \%)$ & $186(77.5 \%)$ & & & & & \\
\hline & Male & $40(30.8 \%)$ & $90(69.2 \%)$ & 17.06 & $<0.001$ & 2.8 & 1.698 & 4.616 \\
\hline \multirow[t]{2}{*}{ Gender } & Female & $40(13.7 \%)$ & $252(86.3 \%)$ & & & & & \\
\hline & Chinese & $44(15.7 \%)$ & $237(84.3 \%)$ & & & & & \\
\hline \multirow[t]{3}{*}{ Race } & Malay & $17(25.4 \%)$ & $50(74.6 \%)$ & 11.85 & 0.008 & & & \\
\hline & Indian & $7(16.3 \%)$ & $36(83.7 \%)$ & & & & & \\
\hline & Others & $12(38.7 \%)$ & $19(61.3 \%)$ & & & & & \\
\hline \multirow[t]{3}{*}{ Nationality } & Malaysian & $72(18.2 \%)$ & $323(81.8 \%)$ & & & & & \\
\hline & $\begin{array}{l}\text { Non- } \\
\text { Malaysian }\end{array}$ & $8(29.6 \%)$ & $19(70.4 \%)$ & 2.13 & 0.116 & 1.88 & 0.796 & 4.885 \\
\hline & Dentistry & $45(19.6 \%)$ & $185(80.4 \%)$ & & & & & \\
\hline \multirow{4}{*}{ Faculty } & Medicine & $12(17.6 \%)$ & $56(82.4 \%)$ & 1.50 & 0.681 & & & \\
\hline & Pharmacy & $13(15.7 \%)$ & $70(84.3 \%)$ & & & & & \\
\hline & Optometry & $10(24.4 \%)$ & $31(75.6 \%)$ & & & & & \\
\hline & Year 1 & $20(16.5 \%)$ & $101(83.5 \%)$ & & & & & \\
\hline \multirow{4}{*}{$\begin{array}{l}\text { Year of } \\
\text { study }\end{array}$} & Year 2 & $18(16.4 \%)$ & $92(83.6 \%)$ & & & & & \\
\hline & Year 3 & $14(19.2 \%)$ & $59(80.8 \%)$ & 6.78 & 0.148 & & & \\
\hline & Year 4 & $22(29.3 \%)$ & $53(70.7 \%)$ & & & & & \\
\hline & Year 5 & $6(14.3 \%)$ & $36(85.7 \%)$ & & & & & \\
\hline
\end{tabular}

\section{DISCUSSION}

Healthcare workers have an important role to play in curbing the global tobacco epidemic ${ }^{16}$. Thus, health care students are expected to have more responsibility and a conscious approach towards tobacco habits. In light of the specific training of primary health care professionals, it seems logical to assume that this group would be more aware of the deleterious health consequences associated with tobacco use, and therefore smoke at lower rates compared to other groups. However, according to a systematic review on prevalence of smoking habits among healthcare workers, the prevalence of smoking has been highly variable between $3 \%$ and $58 \%$, with a pooled prevalence of $21 \%{ }^{17}$. The prevalence of tobacco habits was $19 \%$ in our study which is slightly lesser than the national prevalence of smoking in adults in Malaysia $^{3}$. This means that nearly one fifth of the participating health care students have used tobacco, which is contradictory to the principles of a health care professional in creating awareness about tobacco and providing assistance to quit tobacco, among the public.

In our study, about $98 \%$ of participants had heard about tobacco and were well aware of its harmful effects. This could be related to the fact that the 
effects of tobacco have been a common topic within the curriculum of health science undergraduate courses. However, it was disappointing to see that some of the healthcare students had failed to apply this knowledge to prevent themselves from falling prey to the tobacco habit. The reason for failure of translation of knowledge into action needs further exploration.

In our study, about $95 \%$ of the tobacco users used more than one form of tobacco, with majority of them using cigarette, shisha, and vaping in combination. Studies conducted on healthcare students in other countries also showed a similar trend of increase in other forms of tobacco usage other than cigarette ${ }^{18,19}$. Studies conducted previously on university students in Malaysia showed a high prevalence of shisha use and a general lack of understanding of the dangers involved ${ }^{20,21}$. Shisha and vaping are on par with cigarette smoking, unlike in the past, becoming a new trend among tobacco users, as emphasized in another study ${ }^{22}$. Especially for shisha, which has progressively become a norm activity during socialization among university students, whereby the majority are still unaware of its consequences and assume that shisha is less harmful than cigarette $^{23}$. This calls for inclusion of effects of other forms of tobacco in undergraduate curriculum at a local level, and regulations on other forms of tobacco at a national level.

About $40 \%$ of the tobacco users in our study started using tobacco at a very young age which was between 10 and 20 years. In some studies conducted on smokers, the average age of first time tobacco use was about 15 years ${ }^{19}$. This can be corelated to studies showing prevalence of smoking among school going children in Malaysia ${ }^{24}$. It is considered that children and adolescents who smoke suffer from more serious health problems, have a stronger addiction and are unable to quit easily ${ }^{25}$. Unless the regulations are made more comprehensive to curb this habit at a young age, this trend will continue.

Our study showed a higher prevalence of tobacco use among males as compared to females with the ratio of about $3: 1$. This finding is similar to many studies on tobacco habits conducted among students in Malaysia. This has been attributed to many reasons like cultural, social reasons and also under reporting among females. ${ }^{26}$

Also, in our study, majority of them were influenced by their friends to use tobacco products, peer pressure being the main reason stated. A study by Joseph et $\mathrm{al}^{27}$, found that surrounding friends had become the major influence on the change in habits and lifestyles among students, which may have further increased their self-desire to try on something novel, after indulging in a diverse environment like a university. These findings place demands on parents, family members and educators to be more responsible and monitor the children and students, so that suitable steps for prevention of tobacco habits may be undertaken.

More than half of the tobacco users in our study obtained their products from various stores. This could be attributed to easy accessibility of tobacco products in the immediate vicinity of the university, which is a factor of concern and needs to be seriously dealt with.

Similar to the findings of a study by Wee Lei Hum $^{28}$, in our study, only about $11 \%$ of the users were willing to quit tobacco, despite the fact that about $90 \%$ had seen anti-tobacco warnings on cigarette packs and social media and about 32.5\% were advised to quit tobacco and almost all of them were aware of the harmful effects of tobacco use and passive smoking. This also indicates that tobacco and its effects have not been seriously comprehended by these healthcare professional students. Such an attitude and lack of motivation to quit tobacco among future health professionals could have a devastating effect on the future society.

\section{CONCLUSION}

About one fifth of the health science undergraduate students had used tobacco products in our study reflecting a seemingly inappropriate portrait as compared to their future careers as individuals who could bring huge impacts on the health of the society. It is imperative that their own current tobacco usage be curtailed so as not to have a significant negative impact on their credibility as future healthcare professionals, an impact which ought to be taken into account in tobacco control programmes. Therefore, there is an urgent need for reinforcement of education and assistance on quitting tobacco among the undergraduates of health science faculties as they are the future health care professionals who have to educate the public on the ill effects of various forms of tobacco.

\section{Conflict of interest}

The authors declare no potential conflict of interest.

\section{Acknowledgement}

We would like to thank SEGi University for funding this study. This study is a part of an internal grant of SEGi University (SEGilRF/2016-23/FOD-8/98).

\section{REFERENCES}

1. Charlton A. Medicinal use of tobacco in history. J R Soc Med. 2004;97(6):292-296. 
2. Tobacco-key facts. Available at https://www.who.int/news-room/factheets/detail/tobacco. Accessed (1 June 2020).

3. National health and morbidity survey $\mathbf{2 0 1 5}$ - report on smoking status among Malaysian adults. Available at https: //www.moh.gov.my/moh/resource s/NHMS2015-VolumeV.pdf. Accessed (5 June 2020) .

4. Anthonisen NR, Skeans MA, Wise RA, Manfreda J,Kanner RE, Connett JE. The effects of a smoking cessation intervention on 14.5-year mortality: a randomized clinical trial. Ann Intern Med. 2005;142:233-239.

5. Walsh MM, Ellison JA. Treatment of tobacco use and dependence: the role of the dental professional. J Dent Edu.2005;69:521-537.

6. Ussher M, Chambers M, Adams R, Croghan E, Murray R. Evaluation of a nationally disseminated self-help intervention for smoking cessation "Quit Kit". Tob Control . 2011;20(5):380-382.

7. GTSS Collaborative Grou. Tobacco use and cessation counseling: Global Health Professionals Survey Pilot Study, 10 countries, 2005. Tob Control. 2006 ;15(2):31-34.

8. Rice VH, Stead L. Nursing intervention and smoking cessation: Meta-analysis update. Heart Lung .2006;35:147-163.

9. Gorin SS, Heck JE. Meta-analysis of the efficacy of tobacco counseling by health care providers. Cancer Epidemiol Biomarkers. 2004; 13:2012-2022.

10. Binnie $\mathrm{VI}$, McHugh S, Jenkins $\mathrm{W}$, Borland W, Macpherson LM. A randomized controlled trial of a smoking cessation intervention delivered by dental hygienists: A feasibility study. BMC Oral Health. 2007; 7:5.

11. Sinclair HK, Bond CM, Stead LF. Community pharmacy personnel interventions for smoking cessation. Cochrane Database Syst Rev .2004;(1):CD003698.

12. Smith DR, Leggat PA. An international review of tobacco smoking among medical students. J Postgrad Med. 2007;53:55-62.

13. Sreeramam reddy CT, Ramakrishna redyy N, Rahman M, Mir IA. Prevalence of tobacco use and perceptions of student health professionals about cessation training: results from Global Health Professions Students Survey. BMJ Open. 2018:e017477.

14. Rashid AK, Azizah AM.Smoking habits among medical students in a private university. Malaysian J Public Health Med. 2011;11(1):70-77.

15. Global Youth Tobacco Survey (GYTS)WHO. Available at www.who.int/ tobacco/surveillance/GYTS. Accessed (1 December 2017).

16. WHO. WHO Tobacco Free Initiative. The Role of health professionals in tobacco control: WHO; 2005. Available at: http://www.who.int/tobacco/resources/ publications/wntd/2005/bookletfinal_20 april.pdf Accessed (2 June 2020)

17. Nilan K, McKeever TM, McNeill A, Raw M, Murray RL . Prevalence of tobacco use in healthcare workers: A systematic review and meta-analysis. PLOS ONE.2019; 14(7): e0220168

18. Amin HS, Alomair ANA, Alhammad AHA, et al. Prevalence of Tobacco Product Consumption and Exposure among Healthcare Students in King Saud University in Riyadh, Saudi Arabia. J Community Med Health Educ.2017;7(6):567.

19. Daniel F, Beatriz O, Rosario F, et al. Smoking in nursing students: A prevalence multi center study. Medicine. 2020 ;99(14): e19414.

20. Muzammil, Al Asmari DS, Al Rethaiaa AS, Al Mutairi AS, Al Rashidi TH, Al Rasheedi $\mathrm{HA}$, et al. Prevalence and perception of shisha smoking among university students: A cross-sectional study. J Int Soc Prevent Communit Dent 2019;9:275-81.

21. Wong LP, Alias $\mathrm{H}$, Aghamohammadi N, Aghazadeh S, Hoe VC. Shisha Smoking Practices, Use Reasons, Attitudes, Health Effects and Intentions to Quit among Shisha Smokers in Malaysia. Int J Environ Res Public Health. 2016;13(7):726.

22. Ramachandra SS, Yaldrum A. Shisha smoking: An emerging trend in Southeast Asian nations. J Public Health Policy .2015; 36(3): 304-317.

23. Maziak W, Eissenberg T, Rastam S, et al . Beliefs and attitudes related to narghile (waterpipe) smoking among university 
students in Syria. Ann Epidemiol.2004; 14: 646-654.

24. Lim, K.H., Lim, H.L., Teh, C.H. et al. Smoking among school-going adolescents in selected secondary schools in Peninsular Malaysia- findings from the Malaysian Adolescent Health Risk Behaviour (MyaHRB) study. Tob. Induced Dis. 15, 9 (2017).

25. Letcher T,Greenhalgh EM, Winstanely MH.21 Health effects for younger smokers. In Scollo MM and Winstanley MH editors. Tobacco in Australia: Facts and issues. Melbourne: Cancer Council Victoria;2015. Available from http://www.tobaccoinaustralia.org.au/3 -21-health-effects-for-younger-smokers.
26. Al-Naggar RA, Al-Dubai SR, Al-Naggar TH, Chen R, Al-Jashamy K. Prevalence and of smoking and associated factors among Malaysian University students. Asian Pac J Cancer Prev.2011;12(3):619-24.

27. Ukwayi JK, Eja OF, Unwanede CC. Peer Pressure and Tobacco Smoking among Undergraduate Students of the University of Calabar, Cross River State. Higher Education Studies.2012;2(3):92-101.

28. Wee $\mathrm{LH}$, Chan $\mathrm{CMH}$, Yogarabindranath SN. A Review of Smoking Research In Malaysia. Med J Malaysia.2016;71(1):2941. 